\title{
Taxon K, a complex within the Burkholderia cepacia complex, comprises at least two novel species, Burkholderia contaminans sp. nov. and Burkholderia lata sp. nov.
}

Correspondence

Peter Vandamme

Peter.Vandamme@UGent.be

\author{
Elke Vanlaere, ${ }^{1}$ Adam Baldwin, ${ }^{2}$ Dirk Gevers, ${ }^{1}$ Deborah Henry, ${ }^{3}$ \\ Evie De Brandt, ${ }^{1}$ John J. LiPuma, ${ }^{4}$ Eshwar Mahenthiralingam, ${ }^{5}$ \\ David P. Speert, ${ }^{3}$ Chris Dowson $^{2}$ and Peter Vandamme ${ }^{1}$
}

${ }^{1}$ Laboratorium voor Microbiologie, Universiteit Gent, K. L. Ledeganckstraat 35, B-9000 Gent, Belgium

${ }^{2}$ Department of Biological Sciences, Warwick University, Coventry CV4 7AL, UK

${ }^{3}$ Department of Pediatrics, University of British Columbia, Vancouver, British Columbia, Canada

${ }^{4}$ Department of Pediatrics, University of Michigan, 1150 W. Medical Centre Drive, 8323 MRSB III, Box 0646, Ann Arbor, Ml 48109-0646, USA

${ }^{5}$ Cardiff School of Biosciences, Cardiff University, Cardiff CF10 3TL, UK

The aim of the present study was to re-examine the taxonomic position and structure of taxon $\mathrm{K}$ (also known as group $\mathrm{K}$ ) within the Burkholderia cepacia complex (Bcc). For this purpose, a representative set of strains was examined by a traditional polyphasic taxonomic approach, by multilocus sequence typing (MLST) analysis and by analysis of available whole-genome sequences. Analysis of the $\operatorname{rec} A$ gene sequence revealed three different lineages, designated recA-I, recA-II and recA-III. DNA-DNA hybridization experiments demonstrated that recA-I and recA-Il isolates each represented a single novel species. However, DNA-DNA hybridization values of recA-II strains towards $\operatorname{rec} A$-III strains and among $\operatorname{rec} A$-III strains were at the threshold level for species delineation. By MLST, recA-I isolates were clearly distinguished from the others and represented a distinct lineage referred to as MLST-I, whereas $\operatorname{rec} A-I I$ and $\operatorname{rec} A$-III isolates formed a second MLST lineage referred to as MLST-II. A divergence value of $3.5 \%$ was obtained when MLST-I was compared with MLST-II. The internal level of concatenated sequence divergence within MLST-I and MLST-II was 1.4 and $2.7 \%$, respectively; by comparison with the level of concatenated sequence divergence in established Bcc species, these data demonstrate that the MLST-I and MLST-II lineages represent two distinct species within the Bcc. The latter conclusion was supported by comparison of the whole-genome average nucleotide identity (ANI) level of MLST-I and MLST-II strains with strains of established Bcc species and by a wholegenome-based phylogenetic analysis. We formally propose to classify taxon $\mathrm{K}$ bacteria from the MLST-I and MLST-II lineages as Burkholderia contaminans sp. nov. (with strain J2956 ${ }^{\top}=$ LMG $23361^{\top}=$ CCUG $55526^{\top}$ as the type strain) and Burkholderia lata sp. nov. (with strain $383^{\top}$ $=$ ATCC $17760^{\top}=$ LMG $22485^{\top}=$ CCUG $55525^{\top}$ as the type strain), respectively. The MLST approach was confirmed as a valuable instrument in polyphasic taxonomic studies; more importantly, the cumulative data for about $1000 \mathrm{Bcc}$ isolates analysed demonstrate that the $3 \%$ concatenated sequence divergence level correlates with the 70\% DNA-DNA hybridization or $95 \%$ whole-genome ANI threshold levels for species delineation.

Abbreviations: ANI, average nucleotide identity; Bcc, Burkholderia cepacia complex; MLST, multilocus sequence typing; RFLP, restriction fragment length polymorphism; ST, sequence type.

The GenBank/EMBL/DDBJ accession number for the 16S rRNA gene sequence of strain R-15816 is AM905038, and those of the recA sequences of strains R-23139, R-15816, R-18442, R-20938, R-9896, R-18428, LMG 16227, LMG 23255 and LMG 23253 are respectively AM905032AM905037 and AM922301-AM922303.

ANI values, $\mathrm{G}+\mathrm{C}$ contents, DNA-DNA hybridization results and biochemical characteristics of the novel isolates and details of single-copy core genes used in tree reconstruction are available as supplementary material with the online version of this paper. 


\section{INTRODUCTION}

The Burkholderia cepacia complex (Bcc) comprises a group of closely related organisms that are very versatile (Coenye $\&$ Vandamme, 2003). The organisms can be exploited for biocontrol, bioremediation and plant-growth-promotion purposes, but their capacity as opportunistic bacteria to cause human infections, in particular in cystic fibrosis patients, hampers their use in these biotechnological applications (Parke \& Gurian-Sherman, 2001). The taxonomy of the Bcc has evolved dramatically in the last few years (Coenye et al., 2001). Until recently, the Bcc consisted of nine species with validly published names, but the recognition of Burkholderia ubonensis and the description of an additional five novel species (Vanlaere et al., 2008) has increased the number of Bcc species to 15 . Recent multicentre studies revealed several clusters of isolates that do not group with one of these $15 \mathrm{Bcc}$ species. One diverse group of unclassified Bcc isolates is known as taxon $\mathrm{K}$ or group K (Baldwin et al., 2005; Dalmastri et al., 2005, 2007; Mahenthiralingam et al., 2006; Payne et al., 2005; Vermis et al., 2002) and includes bacteria from human and environmental sources isolated worldwide. These sources include sputum and blood samples of debilitated patients such as cystic fibrosis patients, reservoir water, river water and sediments, soil, roots, animals, industrial and pharmaceutical product contaminants and domestic and personal care products (Mahenthiralingam et al., 2006, 2008; P. Vandamme and A. Baldwin, unpublished data). Moreover, several cases of epidemic transmission of taxon $\mathrm{K}$ strains among cystic fibrosis patients have been reported (Campana et al., 2005; Cunha et al., 2007). The wholegenome sequences of two taxon $\mathrm{K}$ strains, namely Burkholderia sp. 383 (=LMG 22485) (GenBank accession numbers NC_007509, NC_007510 and NC_007511 for the three chromosomes) and the Burkholderia sp. metagenome SAR-1 (Venter et al., 2004) (NC_000028), are publicly available. In an earlier study, two taxon $\mathrm{K}$ isolates were classified as B. cepacia, based on DNA-DNA hybridization experiments (Vermis et al., 2002). However, recA gene and multilocus sequence analyses, which are known to correlate well with Bcc species status (Baldwin et al., 2005; Mahenthiralingam et al., 2000b), allocated these and other taxon $\mathrm{K}$ strains in a distinct clade, suggesting that they may represent a novel Bcc taxonomic group.

The aim of the present study was to re-examine the taxonomic position and structure of taxon K. For this purpose, a set of strains was examined by a traditional polyphasic taxonomic approach, by multilocus sequence typing (MLST) analysis and by analyses of the available whole-genome sequences.

\section{METHODS}

Bacterial strains and growth conditions. In our ongoing diversity studies of Bcc bacteria, about 150 isolates have been identified as taxon $\mathrm{K}$ by means of HaeIII-based recA gene restriction fragment length polymorphism (RFLP) PAGE or recA gene sequence analysis. Twenty of these isolates were selected and used in the present study (Table 1). All strains were routinely cultured on trypticase soy agar (TSA) and incubated at $28{ }^{\circ} \mathrm{C}$ unless indicated otherwise.

DNA preparation. For PCR and RFLP experiments, DNA was prepared by alkaline lysis as described previously (Storms et al., 2004). For DNA-DNA hybridization experiments and determination of the DNA base composition, DNA was prepared as described by Pitcher et al. (1989).

Bcc-specific recA gene PCR. The recA gene (1040 bp) was amplified using primers BCR1 and BCR2 as described by Mahenthiralingam et al. (2000b).

recA RFLP and recA gene sequence analysis. Amplified $r e c A$ fragments were subjected to HaeIII-RFLP analysis (Mahenthiralingam et al., 2000b). Electrophoretic separation of the restriction fragments was performed by PAGE as described by Vanlaere et al. (2005). The restriction patterns were analysed using the BioNumerics 4.5 software package (Applied Maths) and compared with those of Bcc reference strains. recA sequence analysis was performed as described previously (Mahenthiralingam et al., 2000b). Multiple alignment was performed by using the CLUSTAL_x program (Thompson et al., 1997). The aligned sequences were analysed phylogenetically using the BioNumerics 4.5 software. Distances were calculated using the Jukes-Cantor algorithm. Phylogenetic trees based on the neighbour-joining method were constructed with bootstrap values of 1000 replications.

165 rRNA gene sequence analysis. 16S rRNA gene sequence analysis was performed as described previously (Coenye et al., 2001).

Determination of the DNA base composition. DNA was enzymically degraded into nucleosides as described by Mesbah \& Whitman (1989). The nucleoside mixture obtained was separated using a Waters Breeze HPLC system and XBridge Shield RP18 column thermostabilized at $37{ }^{\circ} \mathrm{C}$. The solvent was $0.02 \mathrm{M} \mathrm{NH}{ }_{4} \mathrm{H}_{2} \mathrm{PO}_{4}$ ( $\mathrm{pH} 4.0)$ with $1.5 \%(\mathrm{v} / \mathrm{v})$ acetonitrile. Non-methylated lambda phage DNA (Sigma) and Escherichia coli LMG 2093 DNA were used as calibration reference and control, respectively.

DNA-DNA hybridization experiments. Hybridization reactions were performed with photobiotin-labelled probes in microplate wells as described before (Ezaki et al., 1989; Goris et al., 1998), using an HTS7000 Bio Assay Reader (Perkin-Elmer) for the fluorescence measurements. The hybridization temperature was $50{ }^{\circ} \mathrm{C}$.

MLST analysis. MLST analysis was performed as described before (Baldwin et al., 2005). A phylogenetic tree of concatenated sequences (2773 bp), including fragments of seven genes [atpD (443 bp), gltB (400 bp), gyrB (454 bp), recA (393 bp), lepA (397 bp), phaC (385 bp) and $\operatorname{trp} B(301 \mathrm{bp})]$ from each isolate was constructed based on the neighbour-joining method using MEGA software package version 3 (Baldwin et al., 2005; Kumar et al., 2004). The significance of branching within the trees was evaluated by bootstrap analysis of 1000 computer-generated trees. The program DnaSP version 4.1 (http://www.ub.es/dnasp/DnaSP32Inf.html) was used to calculate the mean number of nucleotide substitutions per site (i.e. the percentage divergence of concatenated allele sequences) between populations based on a Jukes-Cantor method (Naser et al., 2007; Rozas et al., 2003). The standard deviation was calculated to show how widely the values are spread in the dataset. Evidence for clonal or recombining populations was estimated by measuring the extent of linkage [using the standardized index of association $\left(s I_{\mathrm{A}}\right)$ ] between alleles at different loci around the chromosome as described previously (Baldwin et al., 2005; Haubold \& Hudson, 2000; 
Table 1. Bcc taxon $\mathrm{K}$ isolates examined

ATCC, American Type Culture Collection, Manassas, VA, USA; LMG, BCCM/LMG Bacteria Collection, Laboratorium voor Microbiologie, Universiteit Gent, Gent, Belgium; CCUG, Culture Collection, University of Göteborg, Department of Clinical Bacteriology, Göteborg, Sweden; NCIMB, National Collections of Industrial, Marine and Food Bacteria, Bucksburn, Aberdeen, Scotland, UK; NCTC, National Collection of Type Cultures, London, UK; R, Research Collection, Laboratorium voor Microbiologie, Universiteit Gent; other strain numbers are personal designations of the depositor. CF, Cystic fibrosis; ND, not determined.

\begin{tabular}{|c|c|c|c|c|c|c|}
\hline Strain & Other strain designation(s) & Source & Depositor ${ }^{\star}$ & $\begin{array}{c}\text { HaeIII recA } \\
\text { RFLP } \\
\text { PAGE type }\end{array}$ & $\begin{array}{c}\text { recA } \\
\text { sequence } \\
\text { cluster }\end{array}$ & $\begin{array}{l}\text { ST/MLST } \\
\text { group }\end{array}$ \\
\hline \multicolumn{7}{|c|}{$\begin{array}{l}\text { Burkholderia con- } \\
\text { taminans sp. nov. }\end{array}$} \\
\hline LMG 16227 & CCUG 34411 & CF patient (Sweden) & E. Falsen & Se27 & recA-I & 362/MLST-I \\
\hline LMG 23253 & VERONA 53 & CF patient (Italy) & S. Campana & AT & recA-I & $102 \dagger / M L S T-I$ \\
\hline LMG 23255 & 467, ВCС 0823 & CF patient (Czech Republic) & P. Drevinek & AT & recA-I & $102 \dagger / M L S T-I$ \\
\hline LMG $23361^{\mathrm{T}}$ & J2956 ${ }^{\mathrm{T}}$, CCUG $55526^{\mathrm{T}}$ & $\begin{array}{l}\text { Sheep with mastitis, milk } \\
\text { (Spain) }\end{array}$ & $\begin{array}{l}\text { J. R. W. } \\
\text { Govan }\end{array}$ & AT & recA-I & $102 \uparrow /$ MLST-I \\
\hline R-9896 & СЕР0097, 90-530, ВСС0282 & CF patient, blood (USA) & $\begin{array}{l}\text { Own isolate } \\
\text { (D.P.S.) }\end{array}$ & $\mathrm{K}$ & recA-I & 123/MLST-I \\
\hline R-13528 & ВCC0340, СЕР1056 & CF patient, sputum (Canada) & $\begin{array}{l}\text { Own isolate } \\
\text { (D.P.S.) }\end{array}$ & $\mathrm{K}$ & recA-I & 100/MLST-I \\
\hline R-18428 & PC21 & Patient, blood (Brazil) & V. Magalhaes & $\mathrm{K}$ & recA-I & 344/MLST-I \\
\hline R-18442 & PC66 & Patient, blood (Brazil) & V. Magalhaes & $\operatorname{Se} 27$ & $\operatorname{rec} A-\mathrm{I}$ & — /MLST-I \\
\hline R-20938 & 03174009 & CF patient (Sweden) & A. Lagerqvist & $\operatorname{Se} 27$ & recA-I & 362/MLST-I \\
\hline \multicolumn{7}{|c|}{$\begin{array}{l}\text { Burkholderia lata } \\
\text { sp. nov. }\end{array}$} \\
\hline LMG 6860 & NCIB 9091, ATCC 17771 & Forest soil (Trinidad) & NCIMB & AY & recA-II & ND \\
\hline LMG 6863 & $\begin{array}{l}\text { CEP0085, ATCC } 17460, \text { BCC0278, } \\
\text { CDC B2320, NCIB } 9690\end{array}$ & Maraval river (Trinidad) & NCIMB & $\mathrm{K}$ & recA-II & 99/MLST-II \\
\hline LMG 6992 & $\begin{array}{l}\text { CCUG 2857, ATCC 17769, } \\
\text { BCC0174, FC0436, NCIB } 9088\end{array}$ & Soil (Trinidad) & CCUG & $\mathrm{K}$ & $\operatorname{rec} A$-II & 239/MLST-II \\
\hline LMG 6993 & $\begin{array}{l}\text { DSM 50180, ATCC 17770, NCIB } \\
\text { 9089, CCUG } 2858\end{array}$ & Forest soil (Trinidad) & CCUG & Se35 & $\operatorname{rec} A$-II & -/MLST-II \\
\hline LMG $22485^{\mathrm{T}}$ & $383^{\mathrm{T}}$, ATCC $17760^{\mathrm{T}}$, CCUG $55525^{\mathrm{T}}$ & Forest soil (Trinidad) & T. Lessie & K & recA-II & 101/MLST-II \\
\hline LMG 14095 & 290/74, FC0450, ВСС0213 & CF patient (UK) & NCTC & K & recA-III & 300/MLST-II \\
\hline R-3211 & СЕР0088, ВСС0217 & $\begin{array}{l}\text { Patient, cerebrospinal fluid } \\
\text { (USA) }\end{array}$ & $\begin{array}{l}\text { Own isolate } \\
\text { (D.P.S.) }\end{array}$ & $\mathrm{K}$ & recA-III & 98/MLST-II \\
\hline R-9940 & ВСС0335, СЕP1061 & CF patient (Canada) & $\begin{array}{l}\text { Own isolate } \\
\text { (D.P.S.) }\end{array}$ & $\mathrm{J}$ & recA-III & 103/MLST-II \\
\hline R-15816 & 323 & Flower (Brazil) & P. Hebbar & K & recA-III & -/MLST-II \\
\hline R-18628 & BCC0402, B5 & River water (USA) & L. Leff & $\mathrm{J}$ & recA-III & 119/MLST-II \\
\hline R-23139 & AU6262 & CF patient (USA) & $\begin{array}{l}\text { Own isolate } \\
\text { (J. J. L.) }\end{array}$ & $\mathrm{K}$ & recA-III & $\mathrm{ND}$ \\
\hline
\end{tabular}

${ }^{*}$ Depositors (in alphabetical order): S. Campana, Cystic Fibrosis Center, Meyer Hospital, University of Florence, Florence, Italy; E. Falsen, CCUG; J. R. W. Govan, Cystic Fibrosis Microbiology Laboratory and Strain Repository, Medical Microbiology Division, University of Edinburgh Medical School, Edinburgh, UK; P. Hebbar, USDA-ARS, Plant Science Institute, Alternate Crops Systems Lab, Beltsville, MD, USA; A. Lagerqvist, Institute for Clinical Science, Clinical Bacteriology, Upsalla University, Upsalla, Sweden; L. Leff, Department of Biological Sciences, Kent State University, Kent, OH, USA; T. Lessie, Department of Microbiology, University of Washington Medical School, Seattle, WA, USA; V. Magalhaes, Centro de Pesquisa Experimental, Instituto de Ensino e Pesquisa Albert Einstein, São Paulo, Brazil; P. Drevinek, Cardiff School of Biosciences, Cardiff University, Cardiff, UK. $\nmid$ ST102 gives a perfect match with metagenome SAR-1.

$\ddagger-$, No ST identifier due to incomplete allelic profile.

Maynard Smith et al., 1993). An $s I_{\mathrm{A}}$ not significantly greater than 0 after 1000 computer randomizations suggests that a single species population (monophyletic) is in linkage equilibrium (freely recombining), while a population with an $s I_{\mathrm{A}}$ significantly greater than $0(P<0.001)$ is considered to be in linkage disequilibrium (clonal) (Baldwin et al., 2005; Haubold \& Hudson, 2000). Nucleotide sequences of each allele and allelic profile and sequence types for all strains analysed in this study are available from the Bcc MLST website (http://pubmlst.org/bcc/) developed by Keith Jolley and sited at the University of Oxford (Jolley et al., 2004). 
Determination of shared gene content and average nucleotide identity (ANI) values. At the time of writing, $12 \mathrm{Bcc}$ strains have been included in whole-genome sequencing projects, of which seven whole genomes were used in the present study (unfinished genomes are indicated by asterisks): Burkholderia multivorans ATCC $17616^{*}$ (=LMG 17588), Burkholderia cenocepacia IIIA J2315 ${ }^{\mathrm{T}}$ (=LMG $\left.16656^{\mathrm{T}}\right)$, Burkholderia vietnamiensis G4 (=LMG 22486), Burkholderia dolosa AU0158 $^{*}(=\mathrm{R}-3200)$, Burkholderia ambifaria $\mathrm{AMMD}^{\mathrm{T}}\left(=\mathrm{LMG} 19182^{\mathrm{T}}\right)$ and Burkholderia sp. LMG 22485 and the Burkholderia sp. metagenome SAR-1 (Supplementary Table S1, available in IJSEM Online). In addition, six genomes of other Burkholderia strains and the genome of Cupriavidus metallidurans $\mathrm{CH} 34^{\mathrm{T}}$ were included for comparison with Bcc genomes. All genomes are publicly available and were obtained from the FTP site of the National Center for Biotechnology Information (NCBI) in their version of 25 August 2007, except for $\mathrm{J} 2315^{\mathrm{T}}$, which was produced at the Sanger Institute and which was obtained from $\mathrm{ftp}: / /$ ftp.sanger.ac.uk/pub/pathogens/bc (Supplementary Table S1). The number of protein-coding (annotated) genes in each Bcc genome ranged from 5441 to 7717 , with a mean gene length of $992.16 \mathrm{bp}$.

ANI values were calculated as described by Konstantinidis \& Tiedje (2005a). Whole-genome sequences present an opportunity to produce a more robust and resolved species tree using concatenation of core gene sequences. The set of single-copy orthologous core genes was determined by building gene families using OrthoMCL (Li et al., 2003). Protein sequence alignments were generated in MUSCLE (Edgar, 2004), and poorly conserved regions were automatically trimmed using Gblocks (Castresana, 2000). Maximum-likelihood trees with 100 bootstrap replicates were obtained for a subset of 20000 randomly selected amino acid positions from the concatenated single-copy core gene alignment, using the PhyML algorithm (Guindon \& Gascuel, 2003) with a JTT amino acid substitution matrix (Jones et al., 1992) and a discrete gamma model.

Biochemical characterization. A biochemical characterization was performed as described previously (Henry et al., 1997, 2001).

\section{RESULTS AND DISCUSSION}

\section{recA RFLP and recA gene sequence analysis}

Different HaeII recA RFLP patterns, designated K, AT, Se27, $\mathrm{AY}, \mathrm{Se} 35$ and J, were found among the 20 isolates studied (Table 1). Pattern J has also been observed in B. cenocepacia, Burkholderia stabilis and Burkholderia arboris strains (Mahenthiralingam et al., 2000a; Vanlaere et al., 2008). Therefore, these isolates were further examined by MnlI recA RFLP PAGE, generating unique profiles for each species (data not shown). The 20 strains examined were subjected to $r e c A$ sequence analysis. Similarity of the recA sequences towards established Bcc species was greater than $94 \%$, and the recA sequences of taxon $\mathrm{K}$ isolates constituted one cluster, including Burkholderia metallica, within the Bcc. Within taxon $\mathrm{K}$, several distinct clusters, referred to as recAI, $r e c A$-II and $r e c A$-III, were observed that showed sequence similarities of more than $97 \%$ (Fig. 1).

\section{$16 S$ rRNA gene sequencing and phylogenetic analysis}

The 16S rRNA gene sequences of a representative strain from each recA cluster were examined (LMG 16227, LMG
22485 and R-15816 for clusters recA-I, recA-II and recA-III, respectively). Comparison of these $16 \mathrm{~S}$ rRNA gene sequences with those of other Bcc strains revealed similarity levels above $98 \%$ (data not shown). These values were similar to those obtained between strains of other Bcc species. Similarity levels of less than $97.5 \%$ were calculated towards representatives of other Burkholderia species (data not shown).

\section{DNA-DNA hybridization and determination of the DNA base composition}

DNA-DNA hybridization experiments were performed between representatives of the three recA clusters, $B$. metallica LMG 24274 and B. cepacia LMG $1222^{\mathrm{T}}$ (Supplementary Table S2). DNA-DNA hybridization experiments were also performed between recA-I strain LMG 23253 and type strains of the established members of the Bcc, including B. ubonensis. The mean value obtained among recA-I strains LMG $23361^{\mathrm{T}}$, LMG 23253 and LMG 23255 was $88 \%$ and the value between recA-II strains LMG $22485^{\mathrm{T}}$ and LMG 6863 was $79 \%$, whereas the value obtained between the recA-III strains LMG 14095 and LMG 24274 was $68 \%$. Moderate to high values, in the range of 59 to $64 \%$, were obtained between recA-I and recA-II strains. Moderate to high values of 60 and $66 \%$ were obtained between recA-I and recA-III strains. Somewhat higher values, in the range 66-68\%, were obtained between recA-II and recA-III strains. Values in the range of 61 to $66 \%$ were found between strains of the different recA clusters and B. cepacia LMG $1222^{\mathrm{T}}$ and B. metallica LMG 24274 (Supplementary Table S2). Moderate values (42$62 \%)$ were obtained between recA-I strain LMG 23253 and established Bcc members (data not shown). All strains investigated had G +C contents of $66-68 \mathrm{~mol} \%$, which is typical for Bcc species (Coenye et al., 2001) (Supplementary Table S2). The DNA-DNA hybridization values demonstrate that strains of the three recA clusters are closely related, but may constitute distinct novel species within the Bcc (Wayne et al., 1987). However, cluster recAII and recA-III strains showed DNA-DNA hybridization values at the threshold for species delineation. Additionally, the two cluster recA-III strains examined also exhibited a DNA-DNA hybridization value near the $70 \%$ threshold.

\section{MLST analysis}

Eighteen of 20 taxon K strains selected for the present study were analysed by MLST. Three of these strains consistently yielded incomplete MLST profiles (five genes for R-15816 and R-18442; six genes for LMG 6993), probably due to a sequence variation disrupting the binding site of the amplification primers. Nevertheless, analysis of the remaining loci identified them as taxon K strains (Supplementary Table S3). Data for an additional 21 taxon $\mathrm{K}$ strains examined previously and for the Burkholderia sp. metagenome SAR-1 (Baldwin et al., 2005; Mahenthiralingam et al., 2006; A. Baldwin, unpublished results) strain were also 


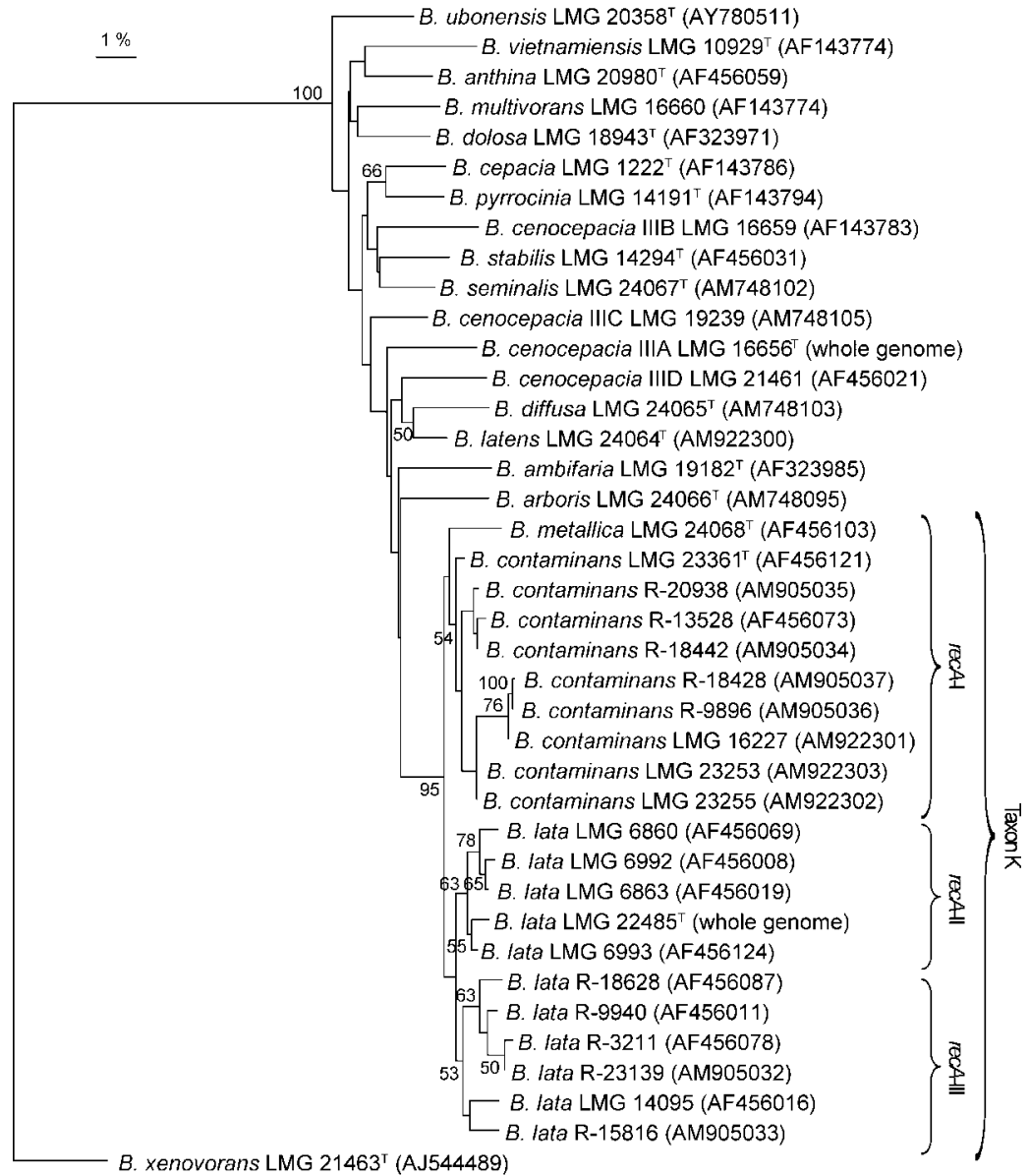

Fig. 1. Phylogenetic tree derived from analysis of $\operatorname{rec} A$ gene sequences of established Bcc species and taxon $\mathrm{K}$ strains. Different $B$. cenocepacia rec $A$ lineages are designated IIIA, IIIB, IIIC and IIID (Vandamme et al., 2003). The tree was constructed using the neighbour-joining method (Jukes \& Cantor, 1969). Accession numbers are given in parentheses. Bootstrap values $(\geqslant 50 \%)$ are shown for 1000 replicates. The sequence of Burkholderia xenovorans LMG $21463^{\top}$ was used as outgroup. Bar, $1 \%$ sequence dissimilarity. included in the present analyses (Supplementary Table S3). Phylogenetic analysis of concatenated sequences demonstrated that the isolates occupied a single clade in the MLST tree which consisted of two clusters, designated MLST-I and MLST-II, supported by bootstrap values of 100 and $92 \%$, respectively (Fig. 2). When these results were compared with results from the recA-based sequence analysis, cluster MLST-I comprised all recA-I strains examined, while cluster MLST-II comprised all recA-II and $r e c A$-III strains examined. Although the recA-II strains formed a distinct lineage supported by a $100 \%$ bootstrap value within MLST-II, they grouped among recA-III strains. The intra- and intertaxon divergence of concatenated nucleotide sequences was calculated for both MLST clusters and for the other members of the Bcc (Fig. 3). Comparison of the percentage divergence of concatenated allele sequences between established Bcc members demonstrated that an average divergence of $3 \%$ can clearly delineate Bcc species. The diversity within Bcc species varies from $0.43 \%$ among $B$. vietnamiensis strains (based on analysis of 29 strains) to $2.89 \%$ within Burkholderia anthina strains (based on analysis of nine strains). Although part of these differences can be attributed to the number of isolates examined for each species, it is clear that the genomes of different Bcc species do not evolve at the same rate. The internal diversity observed within cluster MLST-I was $1.4 \%$, while the value obtained within MLST-II was $2.7 \%$. A divergence value of $3.5 \%$ was obtained when MLST-I was compared with MLST-II.

The MLST data were also used to assign allele types to sequences and allelic profiles and sequence types (STs) to all isolates (Baldwin et al., 2005). Isolates with an identical allelic profile were assigned the same ST identifier and considered to be isogenic, as they were indistinguishable at all seven loci (Baldwin et al., 2005). The 37 taxon $\mathrm{K}$ isolates examined for which a full MLST dataset was obtained were resolved into 27 STs, with ST-102 occurring seven times, ST-98 occurring three times and ST-119 and ST-362 occurring twice. MLST-I and MLST-II strains shared no identical allele types; identical alleles were mainly found within a species and have been observed between the different B. cenocepacia recA subgroups (Baldwin et al., 2005). However, interspecies recombination events were recently reported (Waine et al., 2007). The $s I_{\mathrm{A}}$ value estimating clonality within the clusters MLST-I and MLSTII was $0.180(P<0.01)$ and $0.440(P<0.01)$, respectively (Baldwin et al., 2005; Haubold \& Hudson, 2000). The $s I_{\mathrm{A}}$ values were thus significantly greater than zero, and MLSTI and MLST-II are therefore considered clonal populations. Nevertheless, the values are quite low, which may indicate 


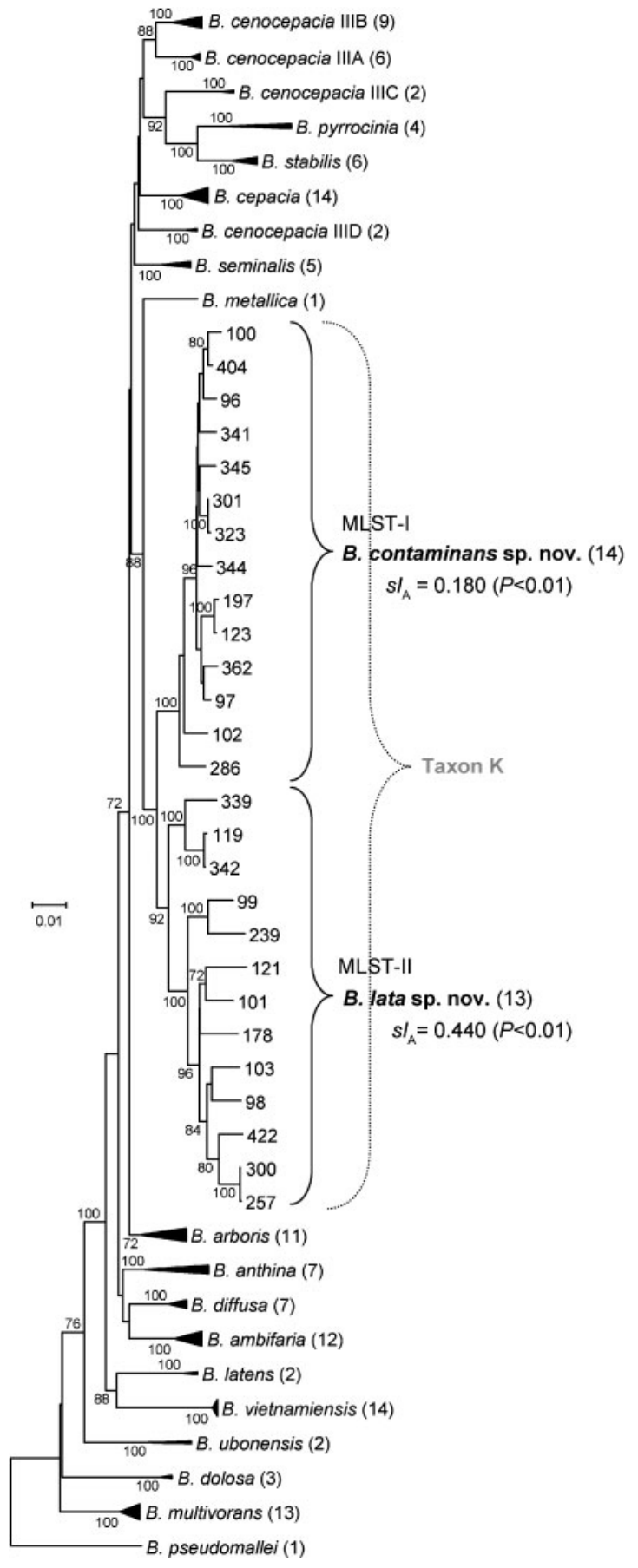

Fig. 2. Phylogenetic analysis of concatenated nucleotide sequences from seven loci, using the neighbour-joining method (performed using MEGA version 3 software). Bootstrap values greater than $70 \%$ are shown for 1000 replicates. Species names of the established species are given and the numbers of STs included in the analysis are indicated in parentheses. Different $B$. cenocepacia lineages are designated IIIA, IIIB, IIIC and IIID (Vandamme et al., 2003). The different STs observed among the taxon $\mathrm{K}$ isolates examined are shown. Burkholderia pseudomallei was used as outgroup. that some recombination is occurring. The $s I_{\mathrm{A}}$ values found were comparable with values observed for B. cepacia strains (Baldwin et al., 2005). Studies of the Bcc have revealed that some species (e.g. B. vietnamiensis and $B$. cenocepacia) recombine more than others (e.g. B. ambifaria) (Waine et al., 2007). Nevertheless, the number of STs for each species is small and, therefore, a much larger sample is required for a more accurate comparison of mechanisms of evolution for each Bcc species.

\section{Determination of shared gene content and ANI values}

The availability of complete genome sequences of many bacteria provides new possibilities for comprehensive demarcation of species (Konstantinidis \& Tiedje, 2005b). In the present study, two genome sequences of taxon $\mathrm{K}$ strains were available. Mahenthiralingam et al. (2006) reported previously that the Burkholderia sp. metagenome SAR-1 was essentially complete and represented taxon K, with the closest sequenced relative being Burkholderia sp. LMG 22485, a strain of cluster MLST-II. The SAR-1 metagenome belongs to ST102 and was genetically identical at multiple random loci when compared to cultivable ST102 isolates (Mahenthiralingam et al., 2006) which reside in MLST-I (Supplementary Table S3). The 100\% nucleotide identity indicated that the genomic sequence of the ST102 SAR-1 metagenome may be used as a surrogate whole-genome sequence for cultivable ST102 isolates such as Burkholderia sp. strain LMG 23361. A whole-genomebased comparison between the cluster MLST-I and MLSTII strains was therefore carried out and compared with genomes of other available $\mathrm{Bcc}$ species, non-Bcc Burkholderia species and members of related genera (listed in Supplementary Table S1).

Goris et al. (2007) demonstrated that the recommended cut-off of $70 \%$ DNA-DNA reassociation for species delineation corresponds to $95 \%$ ANI, a measure for evolutionary relatedness based on sequence similarity between orthologous genes (Goris et al., 2007). The similarity matrix of ANI values of the strains studied is shown in Supplementary Table S1. The ANI values obtained between different Bcc species ranged from 85.04 to $89.92 \%$, whereas the ANI values between Bcc and other Burkholderia species ranged from 75.33 to $81.68 \%$. The ANI value between the Burkholderia sp. metagenome SAR1 and the whole-genome sequence of strain Burkholderia sp. LMG 22485 was $92.71 \%$. This high value confirms the similarity between the two sequences, but is clearly lower than $95 \%$, which corresponds to the established threshold for species delineation (Goris et al., 2007).

A set of 420 single-copy core genes, i.e. orthologous genes present in exactly one copy (no duplicates) in each studied genome, was used to estimate the phylogeny of these bacteria by maximum-likelihood (Supplementary Table S4). The phylogenetic analysis (Fig. 4) revealed that the metagenome SAR-1 and Burkholderia sp. strain 383 were 


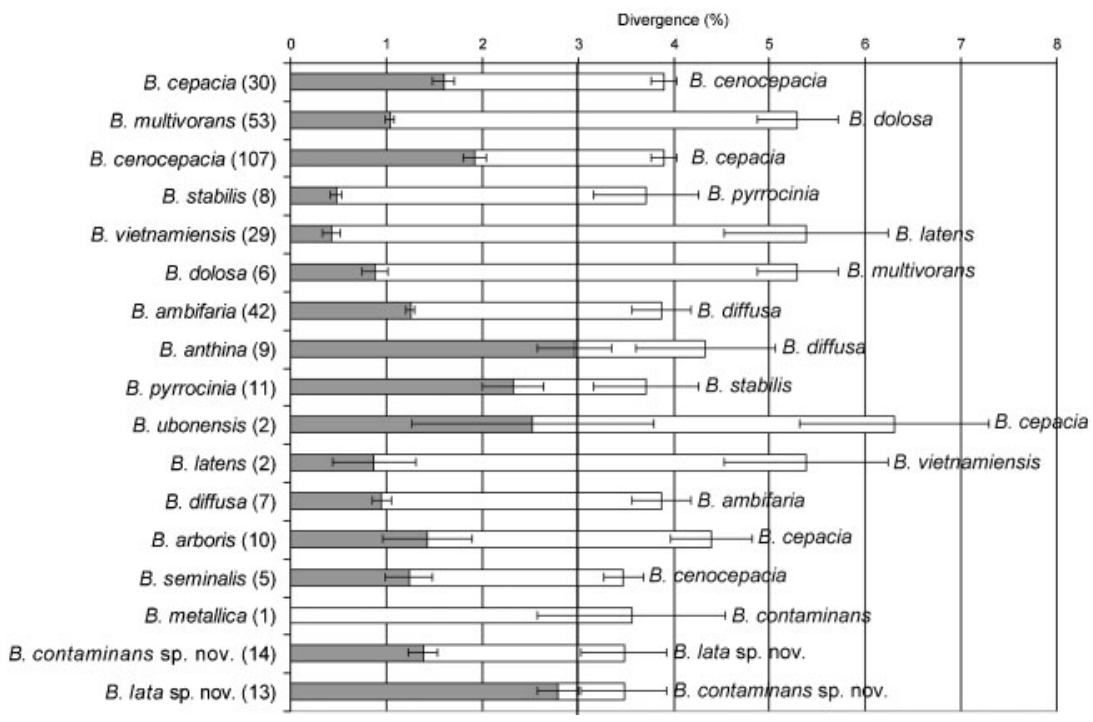

Fig. 3. Concatenated nucleotide sequence divergence of MLST loci. Shaded bars represent the divergence within a species. Open bars represent the divergence between a Bcc species and its closest neighbour (listed to the right) as defined by percentage similarity between concatenated sequences (similar to taxon gap as described by Naser et al., 2007). The number of strains included in the calculations for each species is given in parentheses. $B$. cenocepacia strains represent $\operatorname{rec} A$ lineages IIIA (44), IIIB (57), IIIC (4) and IIID (2). For each bar, the SD is indicated by error bars. The cut-off value of $3 \%$ divergence for species demarcation is marked.

closest neighbours, showing distances that were comparable with those observed between other Bcc species.

\section{Biochemical characterization}

In general, species of the Bcc are phenotypically nearly indistinguishable, making their differentiation quite difficult, even with an extended panel of biochemical tests (Henry et al., 2001). The variable nature of biochemical results for Bcc strains may be due to their unusual genomes, which are among the largest seen in Gramnegative bacteria (6-9 Mb) and which are divided into a minimum of two chromosomal replicons (Lessie et al., 1996; Mahenthiralingam \& Drevinek, 2007). The genomes are rich in insertion sequences, allowing the recruitment of

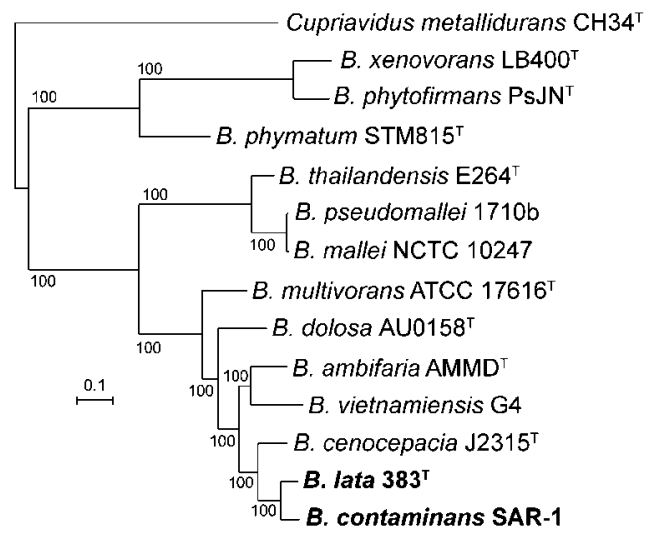

Fig. 4. Whole-genome-based maximum-likelihood tree for Bcc species and other Burkholderia species. The tree was derived from analysis of concatenated single-copy core genes, with $C$. metallidurans $\mathrm{CH} 34^{\top}$ as an outgroup. Bootstrap analysis indicated that the tree was completely resolved. foreign genes (Kenna et al., 2006). Mobile elements such as plasmids, transposons and bacteriophages are also frequently observed (Mahenthiralingam \& Drevinek, 2007). The high foreign and mobile DNA content, in combination with the multireplicon structure, contributes to considerable plasticity and diversity in their genomes which, when differentially expressed in isolates, probably results in their variable biochemical phenotypic profiles.

Biochemical characteristics were determined for seven MLST-I strains and 11 MLST-II strains. A comparison of the biochemical characteristics revealed that these taxa could be distinguished by testing growth at $42{ }^{\circ} \mathrm{C}$ and haemolysis, for which strains of cluster MLST-I were mainly positive. Supplementary Table S5 lists the characteristics that are helpful in distinguishing the two taxa from each other and from established Bcc species. The biochemical characteristics of the novel species are given in the species descriptions below.

\section{Conclusions}

The aim of the present study was to re-examine the taxonomic position and structure of Bcc taxon K. For this purpose, a set of strains was examined by a traditional polyphasic taxonomic approach, by MLST analysis and by analysis of available whole-genome sequences.

Analysis of the recA gene sequences of 20 isolates selected from a collection of over 150 revealed that they represented three different lineages, designated recA-I, recA-II and recAIII (Fig. 1). Analysis of $16 \mathrm{~S}$ rRNA genes and $\mathrm{G}+\mathrm{C}$ contents of isolates representing the three groups confirmed that these bacteria are typical members of the Bcc, but was not helpful in discriminating the different lineages or in distinguishing them from other Bcc bacteria. DNA-DNA hybridization experiments among and between representatives of each lineage demonstrated that recA-I isolates 
represented a single novel species (Supplementary Table S2). recA-II strains represented a second novel species, but these strains showed DNA-DNA hybridization values towards recA-III strains that were at the threshold level for species delineation, i.e. around $70 \%$ (Wayne et al., 1987). Similarly, the two recA-III strains examined exhibited DNA-DNA hybridization near the same threshold (Supplementary Table S2).

MLST analysis of 40 isolates, including 18 that were also analysed by recA sequence analysis, proved very helpful. recA-I isolates were again clearly distinguished from the others and represented a distinct lineage referred to as MLST-I (Fig. 2), recA-II and recA-III isolates formed a second MLST lineage referred to as MLST-II (Fig. 2). The level of concatenated sequence divergence within MLST-I and MLST-II was below $3 \%$ (Fig. 3); by comparison with the level of concatenated sequence divergence in established Bcc species, these data demonstrate that the MLST-I and MLST-II lineages represent two distinct species within the Bcc. The latter conclusion was supported by comparison of the whole-genome ANI of MLST-I and MLST-II strains and of strains of established Bcc species (Supplementary Table S1) and by a whole-genome-based phylogenetic analysis (Fig. 4).

It is clear that the taxonomy and the genomic structure of these bacteria, which typically have genomes in the range of 8-9 Mb organized in multiple replicons, is extremely complex and that the classification of bacteria such as taxon $\mathrm{K}$ requires care. Nevertheless, they represent some of the most common members of the Bcc and require a formal classification and nomenclature. We feel that the data from the present study indicate that these bacteria are best classified into two novel species corresponding with the two MLST lineages. As for most Bcc bacteria, specieslevel identification is cumbersome by biochemical characteristics but can be accomplished readily through DNAbased procedures. In particular, sequence analysis of the recA gene, or of individual or all genes of the MLST scheme, generally yields a straightforward identification result. Nevertheless, in spite of the current 17 established species within the Bcc, several unidentified strains form additional clusters which probably represent novel Bcc species (unpublished data). Pending the availability of a reasonable set of such isolates and a full characterization thereof, the identification of some of these strains may be problematic. We propose to classify taxon $\mathrm{K}$ bacteria from the MLST-I and MLST-II lineages as Burkholderia contaminans sp. nov. and Burkholderia lata sp. nov., respectively. The MLST approach was confirmed as a valuable instrument in polyphasic taxonomic studies. More importantly, the cumulative data for some $971 \mathrm{Bcc}$ isolates analysed (Mahenthiralingam et al., 2008; A. Baldwin, unpublished data) demonstrate that the $3 \%$ concatenated sequence divergence correlates with the $70 \%$ DNA-DNA hybridization or $95 \%$ whole-genome ANI thresholds for species delineation.
Description of Burkholderia contaminans sp. nov.

Burkholderia contaminans [con.ta'mi.nans. L. part. adj. contaminans contaminating, polluting, referring to the metagenome that was recovered from the Sargasso Sea, but which probably represented a sample contaminant; ST102 isolates and other Bcc isolates grew very poorly in seawater, suggesting that the open ocean is not a natural habitat of Bcc species (Mahenthiralingam et al., 2006)].

Cells are Gram-negative, aerobic, non-sporulating rods. Colonies are moist, showing a metallic sheen. All known strains grow on MacConkey agar. Known strains grow on B. cepacia-selective agar and some strains turn that medium alkaline. Growth is observed at 30, 37 and $42{ }^{\circ} \mathrm{C}$. Most strains are yellow pigmented and are haemolytic, a characteristic not commonly observed among Bcc species. The strains assimilate glucose, Larabinose, D-mannose, D-mannitol, $\mathrm{N}$-acetylglucosamine, D-gluconate, caprate, adipate, L-malate, citrate and phenylacetate, but not maltose. Acidification of glucose, maltose, lactose, xylose, sucrose and adonitol is observed. Nitrate reduction is strain dependent, but mostly not present. Activities of oxidase, $\beta$-galactosidase, aesculin hydrolase and lysine decarboxylase and gelatin liquefaction are present, but no ornithine decarboxylase, tryptophanase, arginine dihydrolase or urease activity. The $\mathrm{G}+\mathrm{C}$ content is $67 \mathrm{~mol} \%$. Strains have mostly been isolated from clinical samples, but also from environmental samples. Strains have been involved in a widespread outbreak in the USA due to a contaminated nasal spray (Mahenthiralingam et al., 2006) and as contaminants in a water reservoir supplying a renal dialysis machine in Brazil (Souza et al., 2004).

The type strain is strain $22956^{\mathrm{T}}\left(=\mathrm{LMG} 23361^{\mathrm{T}}=\mathrm{CCUG}\right.$ $55526^{\mathrm{T}}$ ) and was recovered from milk of a sheep with mastitis in Spain during an outbreak in 1999-2000 (Berriatua et al., 2001). The recA RFLP type and a falsepositive PCR test first suggested that this isolate belonged to B. cenocepacia. The type strain is identical in 14 allele sequences to the metagenome SAR- 1 and can be used as a cultured surrogate for research using the SAR-1 metagenome (Mahenthiralingam et al., 2006). Phenotypic and biochemical characteristics are as described above for the species.

\section{Description of Burkholderia lata sp. nov.}

Burkholderia lata (la'ta. L. fem. adj. lata broad, wide, because it is a common Bcc species worldwide).

Cells are Gram-negative, aerobic, non-sporulating rods. Colonies are moist. All known strains grow on MacConkey agar. Strains grow on B. cepacia-selective agar and some strains turn that medium alkaline. Growth is observed at 30 and $37{ }^{\circ} \mathrm{C}$ but not at $42{ }^{\circ} \mathrm{C}$ (except R-18628). Some strains are yellow pigmented or yellow-purple pigmented. No haemolysis (except R-15816). The strains assimilate Dglucose, D-mannose, D-mannitol, $\mathrm{N}$-acetylglucosamine, D- 
gluconate, adipate, L-malate and citrate, whereas the assimilation of maltose, L-arabinose, caprate and phenylacetate is strain dependent. Acidification of D-glucose, maltose, lactose and xylose is observed. Acidification of sucrose and adonitol is strain dependent. Nitrate reduction is strain dependent. Activities of oxidase and lysine decarboxylase are present, but no tryptophanase, arginine dihydrolase or urease activity. Gelatin liquefaction, ornithine decarboxylase, aesculin hydrolase and $\beta$-galactosidase are strain dependent. The variability observed in the $\beta$-galactosidase test is rather uncommon among $\mathrm{Bcc}$ species, which mostly show $\beta$-galactosidase activity. The $\mathrm{G}+\mathrm{C}$ content is $67 \mathrm{~mol} \%$. Most strains have been isolated from diverse environmental and industrial samples, with some isolated from clinical samples. Remarkably, strains identified as recA cluster K-II have only been recovered from environmental samples in Trinidad.

The type strain is strain $383^{\mathrm{T}}$ (=ATCC $17760^{\mathrm{T}}=\mathrm{LMG}$ $22485^{\mathrm{T}}=$ CCUG $55525^{\mathrm{T}}$ ) and was originally recovered from forest soil in Trinidad in 1958 (Stanier et al., 1966). Phenotypic and biochemical characteristics are as described above for the species.

\section{ACKNOWLEDGEMENTS}

E. V. is indebted to the Special Research Council of Ghent University. P.V. and D.G. are indebted to the Fund for Scientific Research Flanders (Belgium) for research grants and a post-doctoral fellowship, respectively. A. B., C. D. and E. M. are indebted to the Cystic Fibrosis Trust UK (grant PJ535) for funding their research. J. J. L. is supported by the Cystic Fibrosis Foundation (USA). D.S. and D.H. are supported by the Canadian Cystic Fibrosis Foundation. We are grateful to all depositors of strains who contributed to this study. We thank Jean Euzéby for his advice on the nomenclature of the novel species B. lata.

\section{REFERENCES}

Baldwin, A., Mahenthiralingam, E., Thickett, K. M., Honeybourne, D., Maiden, M. C., Govan, J. R., Speert, D. P., LiPuma, J. J., Vandamme, P. \& Dowson, C. G. (2005). Multilocus sequence typing scheme that provides both species and strain differentiation for the Burkholderia cepacia complex. J Clin Microbiol 43, 4665-4673.

Berriatua, E., Ziluaga, I., Miguel-Virto, C., Uribarren, P., Juste, R., Laevens, S., Vandamme, P. \& Govan, J. R. (2001). Outbreak of subclinical mastitis in a flock of dairy sheep associated with Burkholderia cepacia complex infection. J Clin Microbiol 39, 990-994.

Campana, S., Taccetti, G., Ravenni, N., Favari, F., Cariani, L., Sciacca, A., Savoia, D., Collura, A., Fiscarelli, E. \& other authors (2005). Transmission of Burkholderia cepacia complex: evidence for new epidemic clones infecting cystic fibrosis patients in Italy. J Clin Microbiol 43, 5136-5142.

Castresana, J. (2000). Selection of conserved blocks from multiple alignments for their use in phylogenetic analysis. Mol Biol Evol 17, 540-552.

Coenye, T. \& Vandamme, P. (2003). Diversity and significance of Burkholderia species occupying diverse ecological niches. Environ Microbiol 5, 719-729.
Coenye, T., Vandamme, P., Govan, J. R. \& LiPuma, J. J. (2001). Taxonomy and identification of the Burkholderia cepacia complex. J Clin Microbiol 39, 3427-3436.

Cunha, M. V., Pinto-de-Oliveira, A., Meirinhos-Soares, L., Salgado, M. J., Melo-Cristino, J., Correia, S., Barreto, C. \& Sá-Correia, I. (2007). Exceptionally high representation of Burkholderia cepacia among B. cepacia complex isolates recovered from the major Portuguese cystic fibrosis center. J Clin Microbiol 45, 1628-1633.

Dalmastri, C., Pirone, L., Tabacchioni, S., Bevivino, A. \& Chiarini, L. (2005). Efficacy of species-specific recA PCR tests in the identification of Burkholderia cepacia complex environmental isolates. FEMS Microbiol Lett 246, 39-45.

Dalmastri, C., Baldwin, A., Tabacchioni, S., Bevivino, A., Mahenthiralingam, E., Chiarini, L. \& Dowson, C. (2007). Investigating Burkholderia cepacia complex populations recovered from Italian maize rhizosphere by multilocus sequence typing. Environ Microbiol 9, 1632-1639.

Edgar, R. C. (2004). MUSCLE: multiple sequence alignment with high accuracy and high throughput. Nucleic Acids Res 32, 1792-1797.

Ezaki, T., Hashimoto, Y. \& Yabuuchi, E. (1989). Fluorometric deoxyribonucleic acid-deoxyribonucleic acid hybridization in microdilution wells as an alternative to membrane filter hybridization in which radioisotopes are used to determine genetic relatedness among bacterial strains. Int J Syst Bacteriol 39, 224-229.

Goris, J., Suzuki, K., De Vos, P., Nakase, T. \& Kersters, K. (1998). Evaluation of a microplate DNA-DNA hybridization method compared with the initial renaturation method. Can J Microbiol 44, 1148-1153.

Goris, J., Konstantinidis, K. T., Klappenbach, J. A., Coenye, T., Vandamme, P. \& Tiedje, J. M. (2007). DNA-DNA hybridization values and their relationship to whole-genome sequence similarities. Int J Syst Evol Microbiol 57, 81-91.

Guindon, S. \& Gascuel, O. (2003). A simple, fast, and accurate algorithm to estimate large phylogenies by maximum likelihood. Syst Biol 52, 696-704.

Haubold, B. \& Hudson, R. R. (2000). LIAN 3.0: detecting linkage disequilibrium in multilocus data. Linkage analysis. Bioinformatics 16, 847-848.

Henry, D. A., Campbell, M. E., LiPuma, J. J. \& Speert, D. P. (1997). Identification of Burkholderia cepacia isolates from patients with cystic fibrosis and use of a simple new selective medium. J Clin Microbiol 35, 614-619.

Henry, D. A., Mahenthiralingam, E., Vandamme, P., Coenye, T. \& Speert, D. P. (2001). Phenotypic methods for determining genomovar status of the Burkholderia cepacia complex. J Clin Microbiol 39, 10731078.

Jolley, K. A., Chan, M.-S. \& Maiden, M. C. (2004). mlstdbNet distributed multi-locus sequence typing (MLST) databases. $B M C$ Bioinformatics 5, 86.

Jones, D. T., Taylor, W. R. \& Thornton, J. M. (1992). The rapid generation of mutation data matrices from protein sequences. Comput Appl Biosci 8, 275-282.

Jukes, T. H. \& Cantor, C. R. (1969). Evolution of protein molecules. In Mammalian Protein Metabolism, vol. 3, pp. 21-132. Edited by H. N. Munro. New York: Academic Press.

Kenna, D. T., Yesilkaya, H., Forbes, K. J., Barcus, V. A., Vandamme, P. \& Govan, J. R. (2006). Distribution and genomic location of active insertion sequences in the Burkholderia cepacia complex. J Med Microbiol 55, 1-10.

Konstantinidis, K. T. \& Tiedje, J. M. (2005a). Genomic insights that advance the species definition for prokaryotes. Proc Natl Acad Sci U S A 102, 2567-2572. 
Konstantinidis, K. T. \& Tiedje, J. M. (2005b). Towards a genomebased taxonomy for prokaryotes. J Bacteriol 187, 6258-6264.

Kumar, S., Tamura, K. \& Nei, M. (2004). MEGA3: integrated software for molecular evolutionary genetics analysis and sequence alignment. Brief Bioinform 5, 150-163.

Lessie, T. G., Hendrickson, W., Manning, B. D. \& Devereux, R. (1996). Genomic complexity and plasticity of Burkholderia cepacia. FEMS Microbiol Lett 144, 117-128.

Li, L., Stoeckert, C. J., Jr \& Roos, D. S. (2003). OrthoMCL: identification of ortholog groups for eukaryotic genomes. Genome Res 13, 2178-2189.

Mahenthiralingam, E. \& Drevinek, P. (2007). Comparative genomics of Burkholderia species. In Burkholderia: Molecular Microbiology and Genomics, pp. 53-79. Edited by T. Coenye \& P. Vandamme. Wymondham, UK: Horizon Bioscience.

Mahenthiralingam, E., Coenye, T., Chung, J. W., Speert, D. P., Govan, J. R., Taylor, P. \& Vandamme, P. (2000a). Diagnostically and experimentally useful panel of strains from the Burkholderia cepacia complex. J Clin Microbiol 38, 910-913.

Mahenthiralingam, E., Bischof, J., Byrne, S. K., Radomski, C., Davies, J. E., Av-Gay, Y. \& Vandamme, P. (2000b). DNA-based diagnostic approaches for identification of Burkholderia cepacia complex, Burkholderia vietnamiensis, Burkholderia multivorans, Burkholderia stabilis, and Burkholderia cepacia genomovars I and III. J Clin Microbiol 38, 3165-3173.

Mahenthiralingam, E., Baldwin, A., Drevinek, P., Vanlaere, E., Vandamme, P., LiPuma, J. J. \& Dowson, C. G. (2006). Multilocus sequence typing breathes life into a microbial metagenome. PLoS One 1, e17.

Mahenthiralingam, E., Baldwin, A. \& Dowson, C. G. (2008) Burkholderia cepacia complex bacteria: opportunistic pathogens with important natural biology. J Appl Microbiol 104, 1539-1551.

Maynard Smith, J., Smith, N. H., O'Rourke, M. \& Spratt, B. G. (1993). How clonal are bacteria? Proc Natl Acad Sci U S A 90, 4384-4388.

Mesbah, M. \& Whitman, W. B. (1989). Measurement of deoxyguanosine/thymidine ratios in complex mixtures by high-performance liquid chromatography for determination of the mole percentage guanine + cytosine of DNA. J Chromatogr 479, 297-306.

Naser, S. M., Dawyndt, P., Hoste, B., Gevers, D., Vandemeulebroecke, K., Cleenwerck, I., Vancanneyt, M. \& Swings, J. (2007). Identification of lactobacilli by pheS and $r p o A$ gene sequence analyses. Int J Syst Evol Microbiol 57, 2777-2789.

Parke, J. L. \& Gurian-Sherman, D. (2001). Diversity of the Burkholderia cepacia complex and implications for risk assessment of biological control strains. Annu Rev Phytopathol 39, 225-258.

Payne, G. W., Vandamme, P., Morgan, S. H., LiPuma, J. J., Coenye, T., Weightman, A. J., Jones, T. H. \& Mahenthiralingam, E. (2005). Development of a recA gene-based identification approach for the entire Burkholderia genus. Appl Environ Microbiol 71, 3917-3927.

Pitcher, D. G., Saunders, N. A. \& Owen, R. J. (1989). Rapid extraction of bacterial genomic DNA with guanidium thiocyanate. Lett Appl Microbiol 8, 151-156.
Rozas, J., Sanchez-Delbarrio, J. C., Messeguer, X. \& Rozas, R. (2003). DnaSP, DNA polymorphism analyses by the coalescent and other methods. Bioinformatics 19, 2496-2497.

Souza, A. V., Moreira, C. R., Pasternak, J., Hirata, M. L., Saltini, D. A., Caetano, V. C., Ciosak, S., Azevedo, F. M., Severino, P. \& other authors (2004). Characterizing uncommon Burkholderia cepacia complex isolates from an outbreak in a haemodialysis unit. J Med Microbiol 53, 999-1005.

Stanier, R. Y., Palleroni, N. J. \& Doudoroff, M. (1966). The aerobic pseudomonads: a taxonomic study. J Gen Microbiol 43, 159-271.

Storms, V., Van Den Vreken, N., Coenye, T., Mahenthiralingam, E., LiPuma, J. J., Gillis, M. \& Vandamme, P. (2004). Polyphasic characterisation of Burkholderia cepacia-like isolates leading to the emended description of Burkholderia pyrrocinia. Syst Appl Microbiol 27, 517-526.

Thompson, J. D., Gibson, T. J., Plewniak, F., Jeanmougin, F. \& Higgins, D. G. (1997). The CLUSTAL_X windows interface: flexible strategies for multiple sequence alignment aided by quality analysis tools. Nucleic Acids Res 25, 4876-4882.

Vandamme, P., Holmes, B., Coenye, T., Goris, J., Mahenthiralingam, E., LiPuma, J. J. \& Govan, J. R. (2003). Burkholderia cenocepacia sp. nov. - a new twist to an old story. Res Microbiol 154, 91-96.

Vanlaere, E., Coenye, T., Samyn, E., Van Den Plas, C., Govan, J., De Baets, F., De Boeck, K., Knoop, C. \& Vandamme, P. (2005). A novel strategy for the isolation and identification of environmental Burkholderia cepacia complex bacteria. FEMS Microbiol Lett 249, 303-307.

Vanlaere, E., LiPuma, J. J., Baldwin, A., Henry, D., De Brandt, E., Mahenthiralingam, E., Speert, D., Dowson, C. \& Vandamme, P. (2008). Burkholderia latens sp. nov., Burkholderia diffusa sp. nov., Burkholderia arboris sp. nov., Burkholderia seminalis sp. nov. and Burkholderia metallica sp. nov., novel species within the Burkholderia cepacia complex. Int J Syst Evol Microbiol 58, 1580-1590.

Venter, J. C., Remington, K., Heidelberg, J. F., Halpern, A. L., Rusch, D., Eisen, J. A., Wu, D., Paulsen, I., Nelson, K. \& other authors (2004). Environmental genome shotgun sequencing of the Sargasso Sea. Science 304, 66-74.

Vermis, K., Coenye, T., Mahenthiralingam, E., Nelis, H. J. \& Vandamme, P. (2002). Evaluation of species-specific recA-based PCR tests for genomovar level identification within the Burkholderia cepacia complex. J Med Microbiol 51, 937-940.

Waine, D. J., Henry, D. A., Baldwin, A., Speert, D. P., Honeybourne, D., Mahenthiralingam, E. \& Dowson, C. G. (2007). Reliability of multilocus sequence typing of the Burkholderia cepacia complex in cystic fibrosis. J Cyst Fibros 6, 215-219.

Wayne, L. G., Brenner, D. J., Colwell, R. R., Grimont, P. A. D., Kandler, O., Krichevsky, M. I., Moore, L. H., Moore, W. E. C., Murray, R. G. E. \& other authors (1987). International Committee on Systematic Bacteriology. Report of the ad hoc committee on reconciliation of approaches to bacterial systematics. Int $J$ Syst Bacteriol 37, 463-464. 